\title{
De Vries's varieties
}

\section{Scientists have always had an irresistible urge to list and classify. But the work of the artist Herman de Vries reminds us that nature's variety will always defy our attempts at imposing a fixed order.}

\section{Martin Kemp}

$\longrightarrow$ he history of natural history revolves around acts of naming and classification. This has most obviously been the case in the Linnaean and Darwinian eras, in which the concept of the species assumed such centrality. But it is equally true of those eras in which the name of something served to inscribe it in the book of nature and declared its symbolic significance within God's treasury of wonders.

Naming and taxonomy are tools, functionally apposite according to the demands of the users. The systems accordingly vary across different cultures, by place and time.

Herman de Vries, the Dutch artist, philosopher and poet, is a collector of natural things - things of a kind. But his 'kinds' stand in a complex and often challenging relationship to standard taxonomic categories, such as those in the herbaria and aboreta in which he has worked.

Since 1970 he has been exhibiting collections - of shells, flowers, leaves, branches, herbs and varieties of earth - which can sometimes be packaged intellectually in the standard fashion but which often resist the process of separation that denomination entails. So his montages of earths alert us to a multitudinous variety which far outstrips our leaden vocabulary.

He has a collection of more than 2,400 samples of earth, including no less than 300 from Gröningen in Holland and 350 from the volcanic island of Gomera in the Canaries. They are laid out according to criteria of similarity and difference, but not within rigid categories. The visual differences in the 'element' (in the ancient sense) that is the basis of so much life speak by implication of the manifold variations in the lives of plants and of the wonderful attuning of their physiologies to minute variations in the compositions of soils.

De Vries's art involves the quiet contemplation of nuances. But it is also quietly subversive. When he exhibits collections of herbal substances, rich in odour, he plays to sensory perceptions even more resistant to exact naming than objects of sight. When he records the sounds of the world he alerts us to a natural music which does not lend itself to conventional notation.

When he writes without capital letters, as he has done for 20 years, he intends to signal

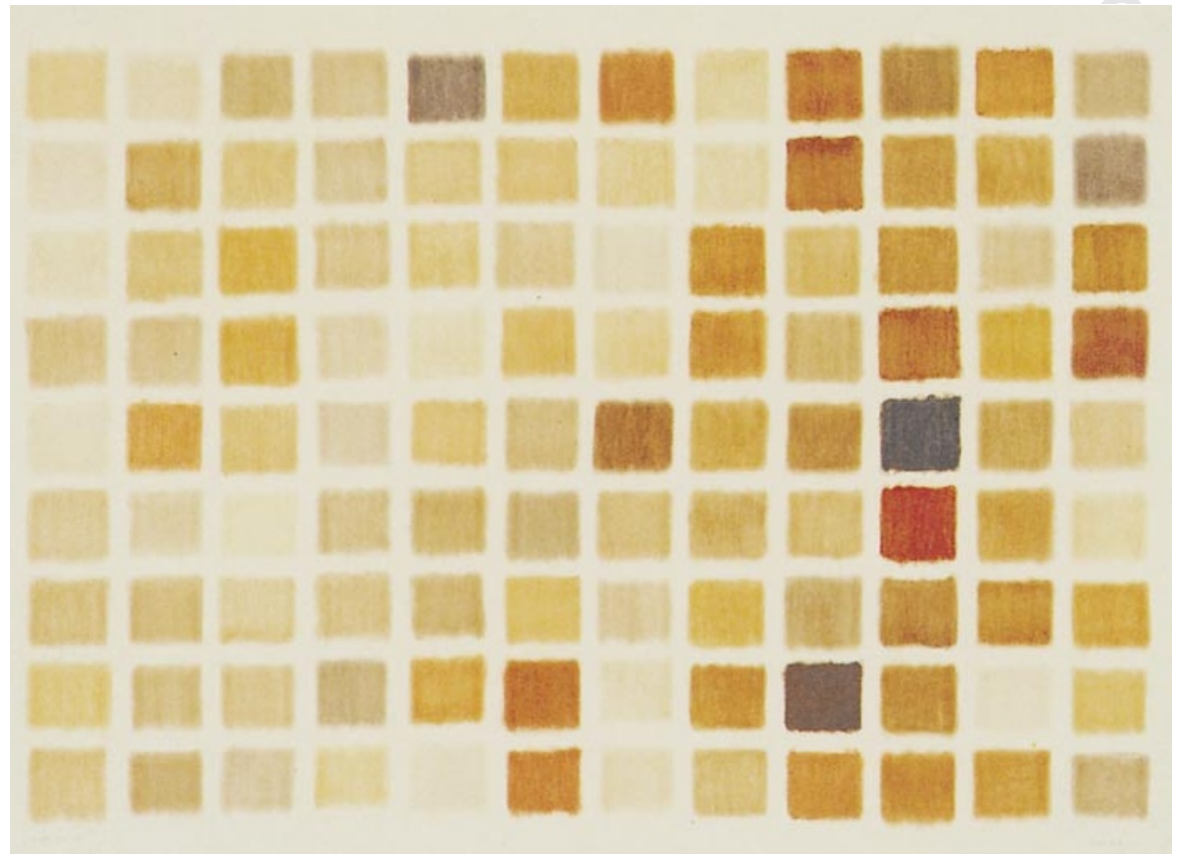

De Vries's from earth; nepal and india (earth on paper), 1992.

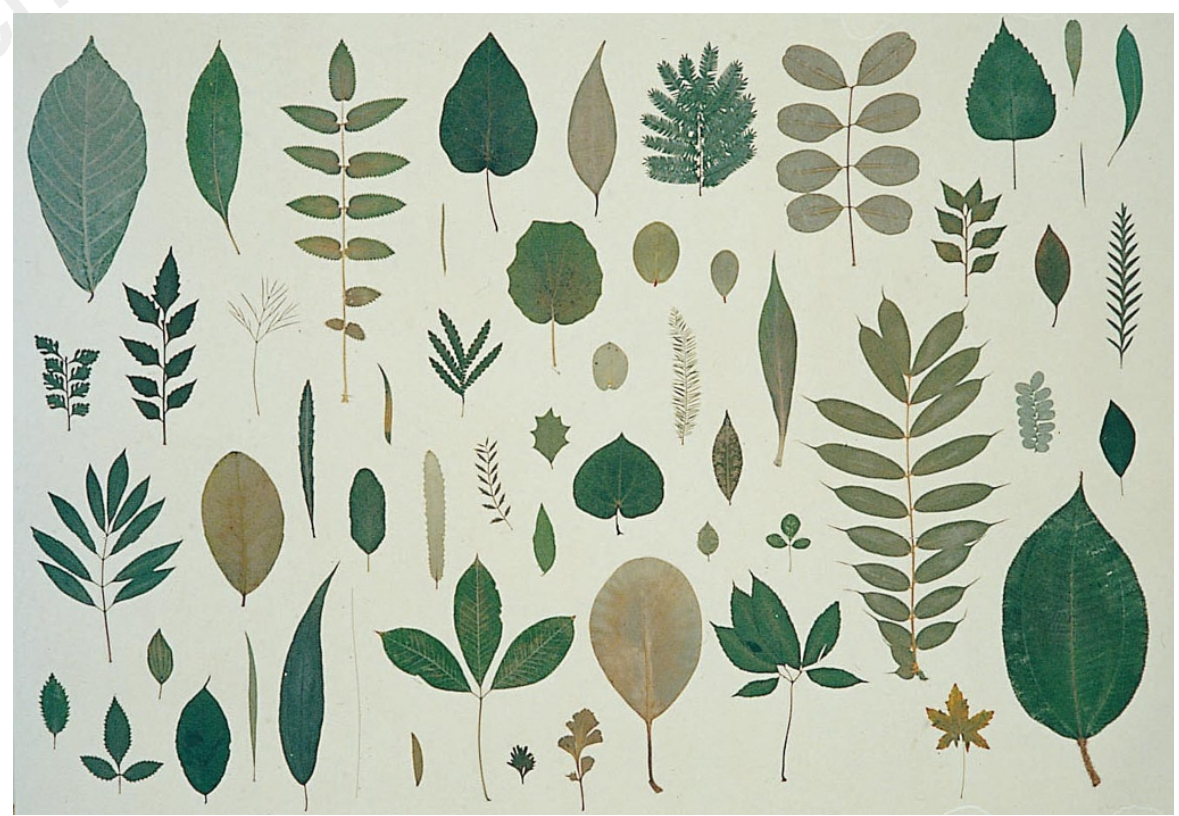

De Vries's forms from the botanic garden (leaves on paper), 1991-92.

"a kind of anti-hierarchic expression. it's the same in nature; every part has its own function, so why should a tree be more important than a diatom?... language is 'you and me', 'we and them', 'here and there', whereas in effect, it is all part of the same, it's one. language... gives us a grip on reality and great social power, but we also pay for it in the loss of unity."

His book of nature has no rigidly pre- scribed lists of flora and fauna. He invites us to sense anew, so that we can sense affinities across boundaries. He also alerts us to pages torn out - as in his book in memory of scottish forests - forests still named on some maps but whose absence testifies to the perils of collective insensitivity.

Martin Kemp is in the Department of the History of Art, University of Oxford, 35 Beaumont Street, Oxford OX12PG, UK 